\title{
A sátira em Luiz Gama: uma leitura do poema "Quem sou eu?"
}

\author{
The satire in Luiz, Gama: a poem reading "Quem sou eu?"
}

\author{
Allyne de Oliveira Andrade* \\ Universidade Federal de Campina Grande \\ Campina Grande, Paraíba, Brasil \\ Naelza de Araújo Wanderley** \\ Universidade Federal de Campina Grande \\ Campina Grande, Paraíba, Brasil
}

Resumo: Um dos aspectos que podemos destacar na obra poética de Luiz Gama é o seu caráter satírico. Como um instrumento de denúncia, a sátira surge a partir de um estado de inconformismo perante algo já estabelecido. Este artigo tem como objetivo observar que aspectos da sátira menipeia estão presentes no poema "Quem sou eu?”, de Luiz Gama. Para tanto, apresentamos uma leitura interpretativa do poema destacando as características da sátira. Nossa fundamentação teórica se baseou nas importantes reflexões de Bakhtin (1981) e Frye (1973) acerca da sátira. Ao final de nossa leitura pudemos observar que as considerações feitas por Bakhtin (1973) e Frye (1981) sobre a sátira se assemelham, em alguns pontos, e se complementam, em outros, e que a leitura desses aspectos satíricos nos ajudam a compreender o processo de construção do poema de Luiz Gama.

Palavras-chave: Sátira. Luiz Gama. Poema

Abstract: One of the aspects that can be highlighted in Luiz Gama's poetic work is its satirical character. As an instrument of denunciation, satire arises from a state of nonconformity in the face of something already established. This paper aims to observe which aspects of menippean satire is present in the poem "Quem sou eu?" By Luiz Gama. For this purpose, it is presented an interpretative reading of the poem emphasizes the characteristics of satire. This paper's theoretical backgroundwas based on Bakhtin's important reflections (1981) e Frye (1973) about the satire. At the end of our reading, we could observe that Bakhtin's (1973) and Frye's (1981) considerations of satire resemble, in some points, and complement each other, in other angles, and the reading of these satirical aspects gives us support to figure out the process of constructing Luiz Gama's poem.

Keywords: Satire. Luiz Gama. Poem.

\section{INTRODUÇÃO}

A obra do poeta Luiz Gama é conhecida pelo seu lado cômico e mordaz. Embora esteja vinculado à segunda geração do Romantismo no Brasil, seus poemas revelam uma aproximação maior com a terceira fase, ligada à sátira social. O viés satírico é o aspecto mais central de sua obra, por isso seus poemas tornam-se atuais, sobretudo do ponto de vista temático. Poemas como "Sortimentos de gorras para gente do grande tom", "Quem sou eu?", "Lá vai um verso" e "Pacotilha" revelam a

\footnotetext{
* Graduada em Letras- Língua Portuguesa pela Universidade Federal de Campina Grande (UFCG). Email: allyne_ufcg@outlook.com.

** Professora Associada da Universidade Federal de Campina Grande. Doutora em Letras pela Universidade Federal de João Pessoa (UFPB). E-mail: naelzanobrega@gmail.com.
} 
diversidade de temas e a percepção do poeta sobre a sociedade brasileira de sua época. Atualmente tem crescido o número de estudos sobre a obra de Luiz Gama e, aos poucos, os seus poemas, mesmo que de modo fragmentado, têm chegado, inclusive, ao contexto da sala de aula, bem como sua história enquanto abolicionista. A concepção de sátira menipeia formulada por Bakhtin (1981) liga-se de modo importante com a obra de Luiz Gama, por isso em nosso trabalho destacaremos algumas características pontuadas pelo teórico russo, bem como as contribuições de Frye (1973) acerca da sátira.

Neste artigo, apresentamos alguns apontamentos sobre a sátira menipeia e fazemos uma leitura do poema “Quem sou eu?”, de Luiz Gama. O nosso trabalho tem como objetivo observar quais aspectos da sátira menipeia estão presentes no poema. Quanto à escolha do poema, se deu pela atualidade dos temas sociais arrolados, como a corrupção, o preconceito, a miscigenação, entre outros.

A nossa pesquisa de caráter interpretativo e a nossa metodologia é incorporada à análise, uma vez que partimos sempre do poema para fazer nossas afirmações. Em relação à estrutura, o presente artigo é constituído por dois tópicos. No primeiro, são apresentados alguns apontamentos acerca da sátira tendo como aporte teórico a discussões de Bakhtin (1981) - este sobre a sátira menipeia - e Frye (1973). No segundo tópico fazemos a leitura interpretativa do poema "Quem sou eu?", de Luiz Gama, ressaltando o teor satírico. Por fim, apresentamos algumas considerações finais que abordam a significativa contribuição da poesia de Luiz Gama e dos estudos sobre a sátira.

\section{APONTAMENTOS SOBRE A SÁTIRA MENIPEIA}

Neste tópico apresentaremos duas concepções sobre sátira, as de Bakhtin (1981) e Frye (1973), que consideramos pertinentes para o nosso estudo. Ao longo deste trabalho, observaremos que os aspectos da sátira apontados por Bakhtin dialogam com os de Frye no que se refere à crítica às instituições sociais, à censura política e de costumes.

Bakhtin (1981) realizou um estudo importante sobre a obra de Dostoiévski, em que descreve de maneira detalhada a "sátira menipeia", a qual se aproxima dos aspectos que iremos analisar no poema de Luiz Gama. Segundo o teórico russo, na Antiguidade clássica formaram-se vários gêneros, diversos exteriormente, mas interiormente parecidos.

Os antigos compreendiam a originalidade do campo cômico-sério e o colocavam como oposição aos gêneros sérios como a epopeia, a tragédia e a retórica. Para Bakhtin (1981), esses gêneros estão ligados através de uma relação com o folclore carnavalesco, variando de grau. O teórico chama de literatura carnavalizada à 
literatura que "direta ou indiretamente sofreu influência de diferentes modalidades e folclore carnavalesco (antigo ou medieval)" (p. 92). Em seguida, Bakhtin aborda três peculiaridades exteriores de gênero do campo cômico-sério. A primeira refere-se ao tratamento dado à realidade, à atualidade viva e não ao passado absoluto de mitos e lendas. A segunda não se dissocia da primeira, nela os gêneros do cômico-sério não se baseiam na lenda, mas, sim, na experiência e na fantasia livre. E a terceira refere-se à pluralidade de estilos e à variedade de vozes, caracterizando-se pela fusão do sublime e do vulgar, do sério e do cômico.

Em seu texto, Bakhtin faz uma abordagem sobre a variedade dialógica presente nas obras de Dostoiévski. Nessa variedade, o teórico considera determinantes dois gêneros do campo cômico-sério: o diálogo socrático e a sátira menipeia. De acordo com Bakhtin, o diálogo socrático é impregnado da cosmovisão carnavalesca. No começo, na fase literária de seu desenvolvimento, "era quase um gênero memorialístico: eram recordações/anotações das palestras proferidas por Socrátes, organizadas numa breve narração" (BAKHTIN, 1981, p. 94).

Conforme o teórico, o "diálogo socrático" durou pouco, mas a partir do seu processo de desintegração formaram-se outros gêneros dialogais, dos quais ele destaca a "sátira menipeia". Bakhtin afirma que não podemos considerar a sátira como "produto genuíno do diálogo socrático" (p. 96), pois suas origens remontam diretamente ao folclore carnavalesco cuja influência é mais determinante do que no diálogo socrático.

No tocante às menipeias, Bakhtin (1981) apresenta algumas características desse gênero que estão organizadas em catorze tópicos. Em nossa leitura utilizaremos apenas aquelas que se aproximam do poema de Luiz Gama. No entanto, entendemos que é importante destacar, resumidamente, todas essas características:

1. Elevação excessiva do elemento cômico;

2. Liberdade de invenção temática e filosófica, bem como de limitações históricomemorialísticas; livre de lendas, a menipeia não está presa às exigências da verossimilhança externa;

3. A fantasia e a aventura são interiormente motivadas e justificadas pelo fim filosófico e ideológico. Aqui a fantasia se relaciona com a provocação e a experimentação da verdade. "Com este fim, os heróis da menipeia sobem aos céus, descem ao inferno (...) são colocados em situações extraordinárias reais" (BAKHTIN, 1981, p. 130);

4. A menipeia apresenta uma combinação do fantástico livre e do simbolismo e, às vezes, o elemento místico-religioso liga-se com o naturalismo de submundo (referindo-se às camadas mais baixas da sociedade), extremado e grosseiro; 
5. A menipeia mistura a ousadia da invenção e do fantástico com um universalismo filosófico, apoiando-se numa reflexão sobre a vida humana;

6. Manifestação de uma estrutura em três planos, em que as ações e as síncrises (confrontos) dialógicas se deslocam da Terra para o Olimpo e para o inferno. A representação do inferno teve grande importância nesse gênero, onde surgiu o específico "diálogo dos mortos difundido na literatura europeia do Renascimento, dos séculos XVII e XVIII";

7. Aparecimento da modalidade do fantástico experimental, ou seja, a observação de fenômenos feita de um ângulo de visão inusitado;

8. Experimentação moral e psicológica. Representação da loucura, da dupla personalidade, do devaneio, de sonhos extraordinários e suicídio. "As fantasias, os sonhos e a loucura destroem a integridade épica e trágica do homem";

9. O uso de novas categorias como a excentricidade, o escândalo. Declarações inoportunas, violações às normas e às etiquetas comportamentais e de discursos. "A 'palavra inoportuna' é inoportuna por sua franqueza cínica ou pelo desmascaramento profanador do sagrado";

10. Jogos com passagens e mudanças abruptas, presença de oximoros, antíteses e contradições violentas;

11. Inserção de elementos da utopia social, introduzidos em forma de sonhos ou viagens por países misteriosos;

12. Inclusão de gêneros intercalados (cartas, novelas, discursos oratórios, simpósios, etc.) e pela fusão dos discursos da prosa e do verso;

13. Os gêneros intercalados reforçam a multiplicidade de estilos e se forma um novo enfoque da palavra, enquanto matéria literária;

14. A presença de temas voltados à literatura político-social, ou publicística, centrados na atualidade; surgimento dos "tipos sociais" em todas as camadas da sociedade. "O caráter jornalístico, a publicística, o folhetinismo e a atualidade mordaz caracterizam, em diferentes graus, todos os representantes da menipeia" (BAKHTIN, 1981, p. 134).

É importante ressaltar que a sátira menipeia se formou no período da desintegração popular nacional, "da destruição de normas éticas que constituíam o ideal antigo do 'agradável' ('beleza-dignidade'), numa época de luta tensa entre inúmeras escolas e tendências religiosas e filosóficas heterogêneas" (BAKHTIN, 1981, p. 102).

Podemos perceber que a menipeia engloba uma cosmovisão carnavalesca, por isso encontraremos a figura do "sacrista" abordada por Luiz Gama sendo destituída de seu discurso moralizante. Como afirma Bakhtin (1981, p. 101), 
A menipeia é plena de contrastes agudos e jogos de oximoros: a hetera virtuosa, a autêntica liberdade do sábio e sua posição de escravo, o imperador convertido em escravo, a decadência moral e a purificação, o luxo e a miséria, o bandido nobre, etc. A menipeia gosta de jogar com passagens e mudanças bruscas, o alto e o baixo, ascensões e decadências, aproximações inesperadas do distante e separado, com toda sorte de casamentos desiguais.

É importante lembrar que o poema que discutiremos adiante apresenta características carnavalescas que se aproximam das características da menipeia. $\mathrm{O}$ carnaval anula as leis, as proibições que determinavam a ordem da vida comum e "todas as formas conexas de medo, reverência, devoção, etiqueta, etc." (BAKHTIN, 1981, p. 105). Ou seja, ele elimina a distância entre os homens, as desigualdades.

Bakhtin finaliza seu estudo sobre a menipeia afirmando que quem preservou as particularidades da menipeia antiga não foi a "memória subjetiva" de Dostoiévski, mas, sim, a "memória objetiva" do gênero com o qual ele trabalhou. Dessa forma, podemos entender antiga sátira menipeia como um gênero que se aproxima do que chamamos atualmente de sátira.

No ensaio "O mythos do inverno: a ironia e a sátira", Frye (1973, p. 220) afirma que duas coisas são essenciais à sátira: "uma é a graça ou humor baseado num senso de grotesco e outra destina-se ao ataque". O satirista deve ter noção da indesejabilidade do seu ataque. Frye (1973) também afirma que o ataque em literatura não pode ser uma expressão de ódio pessoal ou social, pois esse tipo de discurso tem um alcance limitado.

Outra característica abordada por Frye é a comparação do homem com um animal, o que permite uma quebra de valores. De acordo com o autor, "chamar um homem de porco ou jaritaca ou uma mulher de cadela proporciona uma satisfação fortemente limitada, pois muitas das qualidades desagradáveis do animal são projeções humanas" (FRYE, 1973, p. 221).

Discorremos, brevemente, sobre as três primeiras fases da sátira abordadas pelo teórico. De acordo com Frye (1973), a primeira fase corresponde à comédia irônica, na qual não há deslocação da sociedade cômica. A sátira típica desta fase é conhecida como a sátira da norma baixa. "Admite como verdadeiro um mundo cheio de anomalias, injustiças, desatinos e crimes, e, contudo, é permanente e indeslocável" (p. 222). Conforme Frye (1973, p. 224),

Se um satirista apresenta, digamos, um clérigo como tolo ou hipócrita, ele não está, qua satirista, atacando nem um homem nem uma igreja. O primeiro não tem importância literária ou hipotética, e a segunda o leva para fora do alcance da sátira. Ele está atacando um mau homem protegido por sua igreja, e tal homem é um monstro gigantesco: monstruoso porque não é o que devia ser, gigantesco porque é protegido por sua posição e pelo prestígio dos bons clérigos. 
A intenção do satirista ao atacar uma instituição religiosa é, por exemplo, desmascarar uma pessoa moralista que é protegida pela sua igreja por algum motivo. O satirista possui um sentimento de indignação e uma relação de inconformismo com as impunidades de modo geral.

A segunda fase corresponde a uma comédia de fuga. Nesta o herói foge para uma sociedade mais apropriada, sem transformar a sua. Nessa fase a atitude do satirista é pragmática. É também nessa fase que a sátira "mostra a literatura assumindo uma função especial analítica de destruir os cacaréus dos estereótipos, crenças fossilizadas, teorias excêntricas, modas opressivas e todas as outras coisas que impedem a livre movimentação da sociedade" (FRYE, 1973, p. 229).

Já a sátira da terceira fase é conhecida como a sátira elevada. Nesta o satirista "mostrar-nos-á a sociedade, num telescópio, como dignos pigmeus a fazer pose, ou num microscópio, como gigantes horríveis e fedorentos ou transformará seu herói num asno e mostrar-nos-á que parece a humanidade, do ponto de vista de um asno" (FRYE, 1973, p. 230). Observaremos que a primeira fase da sátira e a terceira são as que mais se assemelham à construção do poema de Luiz Gama no sentido de ataque e humor, bem como no ato de selecionar as absurdidades da sociedade com a intenção de desmascarar os "protegidos".

Como podemos observar, as palavras de Frye (1973) e Bakhtin (1981) se complementam, pois ambos apresentam traços acerca da sátira que se ligam e nos ajudarão a entender seu processo de construção em “Quem sou eu?”, de Luiz Gama.

No tópico seguinte, faremos uma apresentação sintética de “Quem sou eu?” e apresentaremos uma leitura do poema, observando aspectos satíricos presentes nele.

\section{UMA BREVE LEITURA DO POEMA “QUEM SOU EU?”}

Em “Quem sou eu?”, Gama aponta os defeitos e vícios de uma sociedade preconceituosa e corrupta. Utilizando a palavra "bode" como metáfora, o autor se dirige aos diversos tipos sociais na tentativa de mostrar que não há diferença entre as pessoas, sobretudo a diferença de cor de pele, tema central de seu poema.

A sátira em Luiz Gama não poupa ninguém, inclusive, os negros. Não há nenhum privilégio direcionado a esse grupo, ou seja, o fato do poeta também ser negro e se afirmar como tal em sua obra, não interfere em seu posicionamento crítico. O poeta critica qualquer espécie de corrupção e hipocrisia nas mais diversas classes, não poupando sequer os "intocáveis" das igrejas, e até mesmo os "deuses" são dessacralizados em seu poema. Para que possamos compreender melhor o poema, consideramos importante disponibilizá-lo na íntegra: 


\section{QUEM SOU EU?}

Quem sou eu? Que importa quem?

Sou um trovador proscrito,

Que trago na fronte escrito

Esta palavra- Ninguém!

(A.E.Zaluar - Dores e flores)

1 Amo o pobre, deixo o rico,

Vivo como o Tico-tico;

Não me envolvo em torvelinho,

Vivo só no meu cantinho;

5 Da grandeza sempre longe

Como vive o pobre monge.

Tenho mui poucos amigos,

Porém bons, que são antigos,

Fujo sempre à hipocrisia,

10 À sandice, à fidalguia;

Das manadas de Barões?

Anjo Bento, antes trovões.

Faço versos, não sou vate,

Digo muito disparate,

15 Mas só rendo obediência

À virtude, à inteligência:

Eis aqui o Getulino

Que no plectro anda mofino.

Sei que é louco e que é pateta

20 Quem se mete a ser poeta;

Que no século das luzes,

Os birbantes mais lapuzes,

Compram negros e comendas,

Têm brasões, não - das Calendas;

$25 \mathrm{E}$ com tretas e com furtos

Vão subindo a passos curtos;

Fazem grossa pepineira,

Só pela arte do Vieira,

$\mathrm{E}$ com jeito e proteções.

30 Galgam altas posições!

Mas eu sempre vigiando

Nessa súcia vou malhando

De tratante, bem ou mal,

Com semblante festival

35 Dou de rijo no pedante

De pílulas fabricante

Que blasona arte divina

Com sulfatos de quinina 
Trabusanas, xaropadas,

$40 \mathrm{E}$ mil outras patacoadas.

Que, sem pingo de rubor

Diz a todos que é DOUTOR!

Não tolero o magistrado,

Que do brio descuidado,

45 Vende a lei, trai a justiça

- Faz a todos injustiça -

Com rigor deprime o pobre

Presta abrigo ao rico, ao nobre,

E só acha horrendo crime

50 No mendigo, que deprime

- neste dou com dupla força,

Té que a manha perca ou torça.

Fujo às léguas do lojista,

Do beato e do sacrista -

55 Crocodilos disfarçados,

Que se fazem muito honrados

Mas que, tendo ocasião,

São mais feros que o Leão

Fujo ao cego lisonjeiro,

60 Que, qual ramo de salgueiro,

Maleável, sem firmeza

Vive à lei da natureza

Que, conforme sopra o vento,

Dá mil voltas, num momento

$65 \mathrm{O}$ que sou, e como penso,

Aqui vai com todo o senso,

Posto que já veja irados

Muitos lorpas enfurnados

Vomitando maldições,

70 Contra as minhas reflexões.

Eu bem sei que sou qual Grilo,

De maçante e mau estilo;

$\mathrm{E}$ que os homens poderosos

Desta arenga receosos

75 Hão de chamar-me Tarelo

Bode, negro, Mongibelo;

Porém eu que não me abalo

Vou tangendo o meu badalo

Com repique impertinente,

80 Pondo a trote muita gente.

Se negro sou, ou sou bode

Pouco importa. O que isto pode?

Bodes há de toda casta

Pois que a espécie é muito vasta...

85 Há cinzentos, há rajados, 
Baios, pampas e malhados,

Bodes negros, bodes brancos,

$\mathrm{E}$, sejamos todos francos,

Uns plebeus e outros nobres.

90 Bodes ricos, bodes pobres,

Bodes sábios importantes,

E também alguns tratantes...

Aqui, nesta boa terra,

Marram todos, tudo berra;

95 Nobres, Condes e Duquesas,

Ricas Damas e Marquesas

Deputados, senadores,

Gentis-homens, vereadores;

Belas damas emproadas

100 De nobreza empantufadas;

Repimpados principotes,

Orgulhosos fidalgotes,

Frades, Bispos, Cardeais,

Fanfarrões imperiais,

105 Gentes pobres, nobres gentes

Em todos há meus parentes.

Entre a brava militança

Fulge e brilha alta bodança;

Guardas, Cabos, Furriéis

110 Brigadeiros, Coronéis

Destemidos Marechais,

Rutilantes Generais,

Capitães de mar-e-guerra

- Tudo marra, tudo berra -

$115 \mathrm{Na}$ suprema eternidade,

Onde habita a Divindade,

Bodes há santificados,

Que por nós são adorados.

Entre o coro dos Anjinhos

120 Também há muitos bodinhos.

$\mathrm{O}$ amante de Syringa

Tinha pêlo e má catinga;

$\mathrm{O}$ deus Mendes, pelas costas,

$\mathrm{Na}$ cabeça tinha pontas;

125 Jove, quando foi menino, Chupitou leite caprino;

E segundo o antigo mito

Também Fauno foi cabrito.

Nos domínios de Plutão,

130 Guarda um bode o Alcorão;

Nos lundus e nas modinhas

São cantadas as bodinhas: 
Pois se todos têm rabicho,

Para que tanto capricho?

135 Haja paz, haja alegria,

Folgue e brinque a bodaria;

Cesse, pois, a matinada,

Porque tudo é bodarrada!

(GAMA, 2000, p. 113-118).

Do ponto de vista estrutural, o poema é composto por uma estrofe única com 138 versos de sete sílabas poéticas (redondilha maior); as rimas que permeiam o poema se assemelham aos dísticos do tipo $\mathrm{AABB}$, embora não permaneçam com as mesmas terminações ao longo do poema. Como se trata de um poema longo, no decorrer de nossa leitura convocaremos alguns versos para exemplificar os aspectos da sátira menipeia presentes nele, como também para ressaltar sua atualidade.

Inicialmente, Luiz Gama traz uma epígrafe extraída do poema "Ninguém", de Augusto Emílio Zaluar (poeta português naturalizado no Brasil), que serve como uma espécie de resumo do que será abordado no poema "Quem sou eu". Podemos observar a epígrafe abaixo:

Quem sou eu? Que importa quem?

Sou um trovador proscrito,

Que trago na fronte escrito

Esta palavra sim - Ninguém!

(A.E.Zaluar - Dores e flores) (GAMA, 2000, p. 113).

Nessa quadra o eu-lírico se apresenta como alguém que foi vetado/banido e enfatiza tal estado ao dizer que traz na fronte a palavra "ninguém". Um aspecto importante de "Quem sou eu?" é o caráter metalinguístico, como na passagem "Faço versos, não sou vate" e ainda na concepção de poeta que aparece no poema. Nos versos 19 a 30, Gama faz uma reflexão sobre essa questão:

Sei que é louco e que é pateta

Quem se mete a ser poeta;

Que no século das luzes,

Os birbantes mais lapuzes,

Compram negros e comendas,

Tem brasões, não - das Calendas,

E com Tretas e com furtos

vão subindo a passos curtos;

Fazem grossa pepineira,

só pela "arte do Vieira"

E com jeito e proteções

Galgam altas posições! (GAMA, 2000, p. 114). 
Observa-se que o poema fala de um eu-lírico que faz versos, mas que não se considera certo tipo de poeta, o vate (o inspirado), pois configura em sua poesia uma função social. Ressaltamos que estamos falando de poeta no sentido romântico, pois podemos verificar que há uma desidealização do romantismo através das palavras pateta/poeta.

O eu-lírico faz referência ao Século das Luzes, remetendo ao Iluminismo movimento intelectual que se desenvolveu durante o século XVIII na Europa e que defendia o uso da razão e do conhecimento - e, por consequência, ao fato de se deparar com situações contrárias a esse movimento, como, por exemplo, a compra de negros e comendas (benefícios concedidos antigamente a eclesiastas e a cavaleiros de ordens militares, sendo que a concessão era feita pelo Papa).

Nos próximos versos, de 43 a 50, veremos o viés satírico do autor de forma mais intensa:

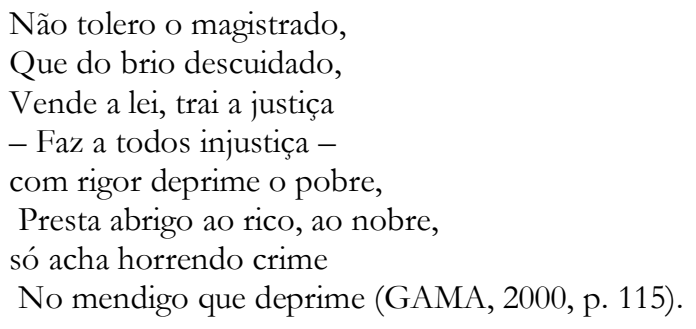

Um dos temas recorrentes na poesia de Luiz Gama é a corrupção. Nas estrofes destacadas acima, pode-se observar a questão da hipocrisia e da corrupção dos magistrados que agem de maneira injusta por não julgar com severidade os nobres, tratando, todavia, os pobres (marginalizados) de modo autoritário.

Outros aspectos da sátira sinalizados por Bakhtin (1981) e Frye (1973) estão presentes no poema. Vejamos os versos abaixo:

Fujo as léguas do lojista,

Do beato e do sacrista -

Crocodilos disfarçados,

que se fazem de honrados,

Mas que tendo ocasião,

São mais feros que o leão (GAMA, 2000, p. 115).

A sátira também tem como característica disseminar princípios morais, visando combater alguns vícios da sociedade de forma sarcástica e é isso que Luiz Gama faz 
nos versos acima. Nas palavras de Frye (1973), “o satirista tem de selecionar suas absurdidades e o ato de selecionar é um ato moral" (p. 220).

Nos versos acima, o poeta não demonstra nenhum tipo de piedade, pelo contrário, expõe de forma crítica sua visão sobre o beato e o sacrista, dessacralizando a imagem de pessoas que deveriam ser exemplos da boa conduta. Dentro dessa perspectiva, podemos perceber um dos traços da sátira menipeia de Bakhtin (1981) as declarações inoportunas, violações às normas e às etiquetas comportamentais de discurso.

Dos versos 81 a 92, o poema assume um caráter cômico devido à utilização do substantivo "bode" como adjetivo, caracterizando alguns tipos sociais citados por Luiz Gama:

Se negro sou, ou sou bode, pouco importa.

$\mathrm{O}$ que isto pode?

bodes há de toda casta,

Pois que a espécie é muito vasta...

Há cinzentos, há rajados,

Baios, pampas e malhados,

Bodes negros, bodes brancos,

e sejamos todos francos,

Uns plebeus e outros nobres,

Bodes ricos, bodes pobres,

Bodes sábios, importantes,

E também alguns tratantes (GAMA, 2000, p. 116).

Nesse momento do poema, Gama utiliza a figura do bode para representar alguns tipos sociais. No artigo "O sonho sublime de um ex-escravo", Ferreira (2013) afirma que Gama "rejeita o sentido negativo de 'negro', bem como o da pejorativa 'bode', aplicada aos mulatos de pele escura". De fato, Gama rejeita o sentido negativo da palavra "negro", mas não retira o sentido pejorativo do "bode", pelo contrário, o poeta retoma o "bode" para reconfigurar a semântica sem valor da palavra e estende seu sentido pejorativo aos brancos (bodes brancos). Nesse sentido, para o poeta o "bode" se torna um signo de alcance amplo e sua função no poema é criticar as mazelas de uma sociedade "embranquiçada".

Uma das características da sátira é a produção do riso. Nas palavras de Bakhtin (1981, p. 98), “a menipeia aumenta globalmente o peso específico do elemento cômico". Podemos notar tal característica nos versos 93 a 100: 


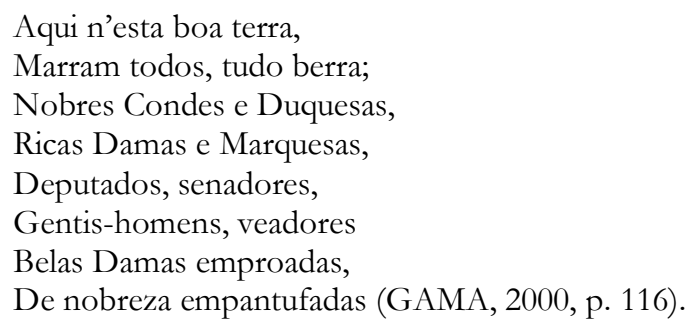

A metáfora de pessoas como bodes que marram produz o riso. A elevação excessiva do elemento cômico e o surgimento dos tipos nas camadas da sociedade são características presentes na sátira menipeia, elementos que Luiz Gama retoma de forma veemente em seu poema. Conforme Bakhtin (1981), "a menipeia gosta de jogar com passagens bruscas, o alto e o baixo, ascensões e decadências" (p. 101). Nos versos acima temos o homem e o bode, os opostos sendo comparados, sobretudo se formos pensar na ausência de refinamento do bode.

Nos últimos versos, Luiz Gama não exclui sequer os deuses, ao aludir à imagem de Jove (deus romano) chupitando leite caprino e também estabelece um vínculo entre Fauno e o bode ao dizer "E segundo antigo mito/ também Fauno foi cabrito" (segundo mito, Fauno seria um deus, protetor dos pastores e rebanhos, que possui cabeça de homem e corpo de bode). Além disso, o poeta desmistifica a imagem de uma prática religiosa ao dizer que "um bode guarda o alcorão".

Segundo Bakhtin (1981), "quase toda denúncia se bastante vigorosa, é seguida pelo leitor com uma espécie de prazer que logo raia o riso". É o que pode ser observado nos versos abaixo:

Na suprema eternidade,

Onde habita a Divindade,

Bodes há santificados,

Que por nós são adorados.

Entre o coro dos Anjinhos

Também há muitos bodinhos. -

O amante de Siringa

Tinha pêlo e má catinga;

O deus Mendes, pelas contas,

$\mathrm{Na}$ cabeça tinha pontas;

Jove quando foi menino,

Chupitou leite caprino;

E, segundo o antigo mito,

Também Fauno foi cabrito.

Nos domínios de Plutão

Guarda um bode o Alcorão;

Nos lundus e nas modinhas 
São cantadas as bodinhas:

Pois se todos têm rabicho,

Para que tanto capricho?

Haja paz, haja alegria,

Folgue e brinque a bodaria;

Cesse, pois, a matinada,

Porque tudo é bodarrada! - (GAMA, 2000, p. 117)

Frye (1973, p. 221) ao discorrer sobre a sátira, afirma que "chamar um homem de porco ou jaritaca ou uma mulher de cadela proporciona uma satisfação fortemente limitada, pois muitas das qualidades desagradáveis do animal são projeções humanas". E é justamente por meio dessa perspectiva que o autor elabora tais comparações com animais.

De modo geral, nota-se que o elemento cômico está presente em todo o poema, mas de forma mais enfática nos últimos versos em que o eu-lírico pergunta: "Pois se todos têm rabicho/ Para que tanto capricho?". Desse modo, o poeta finaliza propondo uma reflexão: se não há diferenças entre os seres humanos, por que alguns se consideram superiores?

\section{CONSIDERAÇÕES FINAIS}

Vimos em nossa leitura que o poema "Quem sou eu?", de Luiz Gama, possui características carnavalescas que se aproximam às da sátira menipeia pontuadas por Bakhtin (1981), como, por exemplo, a anulação das proibições que determinam a vida comum, bem como a eliminação da distância entre os homens. Sabemos que a sátira consiste na censura dos males da sociedade e dos indivíduos e que o satirista assume o papel moralizante. Nesse sentido, Gama, através de sua crítica, tenta chamar atenção para o tratamento desigual entre os homens, sobretudo pela questão de cor de pele, tema central de seu poema.

Durante a leitura do poema, percebemos a presença das seguintes características da sátira menipeia: as declarações inoportunas, as violações às normas e às etiquetas comportamentais e o surgimento dos tipos sociais apresentados por Bakhtin (1981); a comparação do homem com um animal e o humor pontuados por Frye (1973), envolvendo a sátira social. Além disso, podemos afirmar que as discussões de ambos os teóricos acerca da sátira nos ajudaram a compreender a construção satírica presente no poema de Luiz Gama.

Luiz Gama buscava denunciar o falso moralismo da sociedade através de suas poesias satíricas. Tal atitude conferiu à sua poesia um caráter social e revolucionário, o que o aproximou do Realismo. Distanciado da concepção de "vate", Gama utilizou 
a sua poesia não só para satirizar instituições ou tipos sociais, mas também para criticar os "moldes prescritos" pela crítica literária de sua época.

Nosso artigo também se tornou importante por retomar os estudos sobre a poesia de Luiz Gama, tendo em vista que esse autor não é tão estudado quanto outros já cristalizados pela historiografia literária. É válido também ressaltar a atualidade dos temas trabalhados pelo poeta e tentar desmitificar a visão de que o autor tem que se enquadrar em uma geração, tendo em vista que Luiz Gama encontra-se vinculado à segunda geração do Romantismo, mas possui mais características da terceira fase romântica, já próxima do Realismo.

\section{REFERÊNCIAS}

BAKHTIN, Mikhail. Particularidades do gênero e temático-composicionais das obras de Dostoiévski. In:Problemas da poética de Dostoiévski/Mikhail Bakhtin; tradução de Paulo Bezerra. Rio de Janeiro: Ed. Forense- Universitária, p. 87-155, 1981.

FERREIRA, Lígia Fonseca. O sonho sublime de um ex-escravo. Revista de História da Biblioteca Nacional. Rio de Janeiro. 2013. Vol. 9 (p. 66 - 68) 2013.

Disponível em: http://www.revistadehistoria.com.br/secao/capa/o-sonho-sublimede-um-ex-escravo. Acesso em: 05 de setembro de 2019.

FRYE, Northrop. O mythos do inverno: a Ironia e a Sátira. In:Anatomia da Crítica. São Paulo: Cultrix, 1973.

GAMA, Luiz. Primeiras trovas burlescas e outros poemas. Edição preparada por Lígia Fonseca Ferreira. São Paulo: Martins Fontes, 2000. (Coleção Poetas do Brasil)

GOLDSYEIN, NORMA. Versos, Sons, Ritmos.10. ed. São Paulo: Ática, 1998 (Série Princípios).

MARTINS, Nilce Sant'Anna. Introdução à Estilística: A Expressividade na Língua Portuguesa/ Nilce Sant'Anna Martins. São Paulo: T.A Queiroz: Editora da Universidade de São Paulo, 1989.

SILVA, Júlio Romão da. Luís Gama e suas poesias satíricas. 2. ed. Ver. e aum. Rio de Janeiro: Cátedra: Brasília: INL, 1981. 